\title{
A Autonomia e o Desenvolvimento Psicomotor: Um Estudo de Caso Através do Denver II
}

\section{Autonomy and the Developmente Psychomotor: A Case Study Through the Denver II EI Desarrollo Psicomotor y Autonomía: Un Estudio de Caso Através del Denver II}

\author{
Jacqueline de Oliveira Moreira ${ }^{l}$ \\ Diego Alonso Soares Dias \\ Deusdenir de Souza Matis \\ Maria Nazaré de Campos Silva \\ PUC-Minas Gerais
}

\begin{abstract}
Resumo
Este artigo apresenta os resultados parciais da pesquisa "O desenvolvimento psicomotor e a criança prematura: um estudo sobre o processo de aquisição da confiança básica", realizada em 2009 com financiamento da FAPEMIG e do FIP da PUC Minas. A pesquisa teve por principal questionamento as peculiaridades do desenvolvimento psicomotor das crianças prematuras. Investigamos o desenvolvimento psicomotor de crianças pré-termo e a termo com 24 meses, através da aplicação do Teste de Triagem de Desenvolvimento de Denver II e de anamneses com as mães. Relacionamos estas informações com a resolução dos primeiros conflitos - "confiança versus desconfiança" e "autonomia versus vergonha e dúvida" - propostos por Erikson. Os resultados revelam que as crianças prematuras avaliadas na pesquisa apresentam um desenvolvimento psicomotor não adequado se comparadas com as crianças a termo.
\end{abstract}

Palavras-chave: desenvolvimento infantil; prematuridade; Denver II; autonomia.

\begin{abstract}
This article presents the results of the study called "The psychomotor development and the premature child: a study on the process of acquisition of Basic Trust", which was conducted in 2009, funded by FAPEMIG and FIPPUC Minas. The main concern while developing this study were the singularities observed in the psychomotor development of premature children. We investigated the psychomotor development of pre-term and full-term children at the age of 24 months by means of the Denver Developmental Screening Test II, and also by the recollection of the children's medical histories (anamneses), given by their mothers. We related that information to the resolution of the first conflicts - "Basic Trust vs. Mistrust" and "Autonomy vs. Shame and Doubt" - proposed by Erikson. The results reveal that the premature children observed in this study showed less-than-adequate results when compared to the full-term children.

Keywords: child development; prematurity; Denver II; autonomy.
\end{abstract}

\section{Resumen}

Este trabajo presenta los resultados parciales de la investigación "El desarrollo psicomotor y el bebé prematuro: un estudio sobre la adquisición de confianza básica", celebrado en 2009 con el financiamiento de la FAPEMIG y la FIP PUC Minas. La investigación tuvo como principal incógnita las peculiaridades del desarrollo psicomotor de los niños prematuros. Investigamos el desarrollo psicomotor de los niños nacidos prematuros y de aquellos nacidos en el periodo normal de gestación, cuando todos los integrantes de los dos grupos estaban con 24 meses. A través de la aplicación del test de Desarrollo de Denver II y las historias clínicas de las madres, relacionamos esta información con la forma de solucionar los conflictos de la primera etapa de desarrollo - "la confianza frente a la desconfianza" y "autonomía versus la vergüenza y la duda" - propuesta por Erikson. Los resultados muestran que los niños prematuros que fueron evaluados en esta investigación presentan un desarrollo psicomotor no adecuado, cuando son comparados con aquellos niños nacidos en el periodo normal de gestación.

Palabras clave: El desarrollo del niño; niños prematuros ; Denver II; autonomía

\section{Introdução}

A presente pesquisa estruturou-se a partir dos resultados obtidos em pesquisa desenvolvida nos anos de 2007 e 2008, nomeada "O Projeto Mãe Canguru e o processo de construção da relação mãe-bebê”, financiada pela Fundação de Amparo à Pesquisa de Minas Gerais (FAPEMIG) e pelo Fundo de Incentivo à

1 Endereço: Rua Congonhas, 161 - São Pedro. Belo Horizonte, MG. CEP: $31.330-100$
Pesquisa da Pontifícia Universidade Católica de Minas Gerais (FIP-PUC Minas). Nessa pesquisa buscavase uma compreensão das influências exercidas pelo Método Mãe Canguru na construção de uma relação afetiva e significativa entre mãe e criança. A proposta desta pesquisa não abordava o desenvolvimento da criança prematura, afinal, objetivávamos um entendimento a respeito da relação mãe-bebê e suas implicações. Foi a partir de questionamentos referentes a tal desenvolvimento infantil que se organizou o presente projeto, nomeado " $\mathrm{O}$ desenvolvimento 
psicomotor e a criança prematura: um estudo sobre o processo de aquisição da confiança básica", também financiado pela FAPEMIG e pelo FIP-PUC Minas. Neste projeto, nosso principal questionamento foi: quais são as peculiaridades do desenvolvimento psicomotor das crianças prematuras?

Estudar o desenvolvimento psicomotor dessas crianças é fundamental, pois cada vez mais recémnascidos de baixo peso e prematuros têm sobrevivido, em decorrência de avanços tecnológicos e no campo da medicina. Mesmo crianças prematuras que não apresentam sequelas graves podem apresentar comprometimento no seu desenvolvimento neuropsicomotor. Precisamos pensar em estratégias de intervenção, junto a essas famílias, que ofereçam formas terapêuticas e preventivas para essas patologias psicomotoras que prejudicam o crescimento cognitivo, afetivo e social dessas crianças.

Algumas pesquisas no Brasil já foram realizadas, na tentativa de mapear esse imenso campo de trabalho que se refere à intersecção entre o nascimento prematuro e as vicissitudes do desenvolvimento dessas crianças. Isotani, Pedromônico, Perissinoto \& Kopelman (2002) estudaram o desenvolvimento das crianças pré-termo (prematuras) na idade de três anos. A pesquisa conclui que, independente de problemas neurológicos anteriores, as crianças apresentam dificuldades no desenvolvimento e, assim, seria necessária a criação de um sistema de intervenção junto a essas crianças.

Carvalho, Linhares \& Martinez (2001) investigaram o desenvolvimento da aprendizagem e do comportamento de crianças prematuras entre 8 e 10 anos através da Bateria Psicomotora (BPM) de Fonseca (1995) e o teste de inteligência Raven. Os resultados da BPM revelaram problemas respiratórios, enurese noturna, recusa escolar, agitação, agarramento à mãe, impaciência e inquietude em comparação com as crianças na mesma faixa etária nascidas a termo (não prematuras). Méio, Lopes \& Morsch (2003) buscaram explicitar os fatores de prognóstico para o desenvolvimento cognitivo de prematuros de muito baixo peso.

Nossa pesquisa seguiu a esteira dessas supracitadas, mas buscamos investigar o desenvolvimento psicomotor de crianças prematuras com 24 meses, através da aplicação do Teste de Triagem de Desenvolvimento de Denver II e das anamneses com as mães. Relacionamos as informações dessas duas fontes com a resolução dos primeiros conflitos "confiança versus desconfiança" e "autonomia versus vergonha e dúvida" - propostos por Erikson (1998) como estágios do desenvolvimento da personalidade humana. Pensamos que um dos elementos apontados pela pesquisa de Carvalho et al. (2001), a saber, o agarramento à mãe, pode estar relacionado à dificuldade da resolução destes conflitos propostos por Erikson (1998). Se confirmada essa hipótese, este campo relacional entre mãe e filho se constituirá em um excelente espaço de intervenção para facilitar o desenvolvimento psicomotor e, por conseguinte, o desenvolvimento cognitivo e emocional da criança.

Não podemos deixar de mencionar, porém, a advertência anunciada por Magalhães et al. (1999) na utilização do Denver (TDD). As autoras revelam que existem diferenças significativas entre $\mathrm{o}$ desempenho das crianças prematuras brasileiras e a amostragem normativa do TDD, mas essa diferença pode ser resultado da não adaptação do instrumento de avaliação do desenvolvimento motor à população brasileira. Buscando evitar influências de variáveis culturais como fator determinante do resultado do desempenho das crianças, usamos, nesse sentido, o Teste de Triagem de Desenvolvimento de Denver II que foi adaptado para a população brasileira.

Em relação ao seu histórico, segundo Souza, Leone, Takano e Moratelli (2008) "o teste de triagem de Denver, conhecido como Denver Developmental Screening (DDST), publicado em 1967, revisado em 1990 com a denominação de teste de Denver II, vem sendo largamente utilizado, tendo sido padronizado em diversos países", inclusive no Brasil (Souza et al., 2008). Desta forma, é um método de mensuração válido e altamente pertinente para a mensuração de aspectos motores infantis.

No que se refere ao embasamento teórico, para a elaboração da pesquisa, utilizamos também algumas observações de Le Boulch(1986). Seus estudos sobre o desenvolvimento psicomotor das crianças revelam a inter-relação entre motricidade, aprendizagem, inteligência e afetividade (Fonseca, 1995; Le Boulch, 1986). Assim, uma avaliação sobre o desenvolvimento psicomotor fornece subsídios para investigar e intervir junto aos problemas de aprendizagem e afetividade.

Encontramos pesquisas que se dedicam ao estudo dos aspectos psicomotores em crianças com deficiências. Interessa-nos estudar o desenvolvimento psicomotor de crianças prematuras. Quais seriam as dificuldades que essas crianças enfrentam no seu desenvolvimento? Existiria uma dificuldade comum às crianças prematuras? Como podemos contribuir para o enfrentamento dessas dificuldades?

Atentos a essas reflexões proporcionadas por Le Boulch (1992), principalmente as que se referem à inter-relação entre motricidade, aprendizagem, inteligência e afetividade, encontramos em Erikson (1998) um válido subsídio teórico que nos auxiliasse. Este autor desenvolve uma teoria do desenvolvimento a partir de seus conhecimentos sobre a epigênese. Ele propõe uma leitura em que o desenvolvimento psicoafetivo do sujeito humano ocorre através da resolução de conflitos específicos de cada fase.

A criança no primeiro ano de vida precisa resolver o conflito "confiança versus desconfiança". Nessa fase o relacionamento com a mãe é da máxima importância. Se as mães respondem às necessidades 
básicas do bebê, e fornecem meios para que as crianças possam se sentir confiantes para a execução das mais diversas atividades, as crianças desenvolvem uma espécie de segurança básica. Essa segurança é crucial para a exploração do mundo externo e interno e para o enfrentamento do segundo conflito, "autonomia versus vergonha e dúvida", fundamental para que a criança torne-se independente e possa, de forma determinada, buscar aquilo que quer. (Erikson, 1998) Precisamos, pois, saber se esta criança tem um desenvolvimento psicomotor saudável, que permita a exploração deste ambientes e a construção da segurança necessária para a manifestação da autonomia.

\section{Marco Teórico}

Assistimos, hoje, a um aumento dos nascimentos de crianças prematuras, acolhidas em unidades neonatais, que se tornam cada vez mais sofisticadas no que diz respeito à aparelhagem técnica. Todavia, ainda há muito a se conhecer acerca dos efeitos psíquicos desse tipo de nascimento, tanto para a mãe quanto para o bebê. Segundo o Ministério da Saúde (2002), nascem anualmente, em todo o mundo, 20 milhões de crianças prematuras e com baixo peso, e um terço delas morre antes de completar um ano de vida. Como será o futuro das crianças que sobrevivem a um nascimento prematuro?

Por vezes não percebemos a importância do trabalho de acompanhamento do desenvolvimento psicomotor dos bebês como um cuidado para a criação de sujeitos autônomos. Sabemos, no entanto, que os avanços e aquisições psicomotoras constituem um instrumento crucial para o acompanhamento do desenvolvimento infantil. É importante que a equipe de saúde infantil conheça o desenvolvimento normal para que identifique as crianças com desvios e possa estabelecer uma intervenção curativa ou preventiva.

As noções desenvolvimentistas consideram o ser humano como algo biologicamente dinâmico na medida em que, desde o momento do nascimento até a morte, sofre uma série de transformações quantitativas e qualitativas que visam sua evolução. Sabe-se que essas transformações ocorrem em ritmos e intensidades diferenciados, conforme a etapa da vida em que o ser humano se encontra (Guedes \& Guedes, 1997).

Já Erikson (1998) considera que a vida humana é intergeracional e se realiza no que ele chamou Ciclo de Vida, ${ }^{1}$ entendido como o processo de desenvolvimento do ser humano, que começa com a história dos pais, tem continuidade na infância, passa pela idade adulta e termina na velhice. Neste Ciclo, cada fase da vida se relaciona de forma imbricada e profunda com as outras, e cada período da vida tem os seus desafios

1 O Ciclo de Vida foi proposto originalmente em 1950 e suas conquistas. $\mathrm{O}$ autor se preocupa em pensar a inserção da criança num ciclo de vida cujo processo de desenvolvimento segue uma lógica de dependência intergeracional e social-cultural e, portanto, ética. Erikson (1998) não pensa o desenvolvimento apenas como um acontecimento individual, mas como um processo que acontece em uma comunidade que depende das crenças e valores do grupo social.

No primeiro ano de vida o desafio ocorre em torno dos sentimentos de confiança básica e de desconfiança básica. Tanto um quanto o outro, bem como o equilíbrio entre eles, depende essencialmente da mãe e dos cuidados dispensados à criança no começo da vida. Como fica a construção da confiança básica em crianças que sofreram uma separação abrupta do corpo materno por causa de um parto prematuro, e que ainda sofrem a amargura diária de uma internação com intervenções médicas dolorosas?

No intuito de fornecer um panorama geral da teoria de Erikson, é possível citar seus estágios principais, seus subestágios, e também os resultados dos conflitos, que podem ser caracterizados como aquilo que é esperado, ou seja, a qualidade que o ego precisa agregar a si. Os primeiros estágios são os que seguem: "confiança versus desconfiança", que deve ter como resultado a esperança; "autonomia versus vergonha e dúvida", dando origem à vontade; "iniciativa versus culpa", resultando em um propósito. Esses estágios referem-se aos seres que se encontram na infância. Os estágios posteriores são "diligência versus inferioridade", resultando em competência; "identidade versus confusão de identidade", levando à fidelidade; "intimidade versus isolamento", tendo o amor como resultado; "generatividade versus estagnação", que promove a resposta de cuidado; e finalmente, "integridade versus desespero", levando à sabedoria.

O primeiro estágio é de importância fundamental no desenvolvimento infantil, já que ele determinará a capacidade do indivíduo de se relacionar com o ambiente. O resultado aguardado, esperança, será referente às experiências que despertaram certa expectativa sobre o futuro do sujeito. Para Erikson a "esperança conota a qualidade mais básica da condição do 'Eu', sem a qual a vida não poderia começar ou terminar de forma significativa" (Erikson, 1998, p. 56). A esperança é fruto da possibilidade de confiar. O Ser precisa apostar, acreditar na vida para que se possa investir na mesma. Em outras palavras, o que acontece nesse momento permite ao sujeito relacionar-se diante do mundo de tal forma que ele possa desejar e acreditar que aquilo que desejou é possível. Ocorre assim uma adaptação entre a pessoa e o mundo.

O conflito psicossocial que se segue à "confiança versus desconfiança" denomina-se "autonomia versus vergonha e dúvida". Esse conflito tem como resolução o surgimento de uma vontade rudimentar. 
Seu correlato, no que se refere ao desenvolvimento psicossexual, é o estágio anal-uretral muscular, que se vincula a dois movimentos básicos: um retentivo e outro eliminativo (Erikson, 1998). O que o autor nos demonstra, assim, é que a autonomia da criança estará intrinsecamente ligada ao estágio anal, o que remete à importância da linguagem no processo de significação de sensações corporais, muitas vezes de difícil apreensão.

Temos, portanto, a autonomia como decorrente da libidinização de uma zona vital do organismo: o ânus. O que ocorre, contudo, é que essa autonomia tem como seu contraponto os sentimentos de dúvida e de vergonha, oriundos de um senso de derrota devido a excessivos significados duplos conflitantes e um treinamento insuficiente ou exagerado. A principal característica do conflito "autonomia versus vergonha e dúvida" é a de que a criança é chamada a "cuidar de si mesma". A criança é chamada à independência. Os pais, durante esse período, criam duas imagens da criança, às quais ela é constantemente comparada. Uma delas diz daquilo que o sujeito deve vir a se tornar, de forma assertiva e desejada. A outra, por sua vez, é negativa, e relaciona-se àquilo que os pais querem que seja rejeitado, mas que potencialmente faz parte do sujeito. Sobre isso, Erikson ainda acrescenta:

"Tudo isso ocorre num raio de apegos significativos que agora incluem tanto crianças mais velhas quanto pessoas parentais, com a figura do pai sendo vista como cada vez mais fundamental" (Erikson, 1998, p. 44)

\section{Metodologia}

A metodologia utilizada caracteriza-se por ser de cunho qualitativo, uma vez que esta parte do fundamento de que há um vínculo indissociável entre o real e o subjetivo, o que leva a um entrelaçamento essencial entre sujeito e objeto, e por conseguinte, entre mundo objetivo e subjetividade do sujeito (Chizzotti, 1998) . Nossa pesquisa pode ser definida como um estudo de caso, sendo que caso não se restringe a um indivíduo: refere-se a uma comunidade, um grupo, uma instituição (Laville \& Dionne, 1999). Sabemos que essa metodologia é criticada quanto ao tema da representatividade e dos problemas para a generalização (Martins, 2004), pois, como um caso pode ser representativo do conjunto de casos? Associada a essa indagação está a possibilidade de generalização que se baseia na noção estatística de amostra. Todavia acreditamos que, no âmbito das ciências humanas, o estudo de caso permite um maior debruçar sobre temas e favorece as reflexões sobre os diferentes atravessamentos que compõem o quadro social.

Assim sendo, utilizamos o teste Denver II, que se caracterizou por ser um instrumento eficaz na obtenção de dados para análise. Esse teste considera que as aquisições psicomotoras refletem todo o desenvolvimento do sistema nervoso. Dessa forma, ao observarmos o comportamento da criança, suas capacidades físicas e emocionais e suas capacidades intelectuais, nos tornamos aptos a inferir sobre seu nível maturacional (Brêtas, Silva \& Silva, 1995).

Essas observações foram sistematizadas em quatro setores: as capacidades pessoais e sociais; o desempenho motor fino adaptativo; o desempenho motor grosso; e a linguagem. De acordo com Gesell, citado por Brêtas et al. (1995), podemos caracterizar tais setores da seguinte forma: $\mathrm{O}$ item pessoal-social avalia a criança frente a estímulos de caráter social, que relaciona-se à convivência em grupos, às influências sociais e à capacidade de adaptação do sujeito a normas culturais. O item motor fino adaptativo evoca a capacidade motora da criança, incluindo aspectos cognitivos e de capacidade construtiva, englobando movimentos de uma maior precisão.

Relaciona-se à praxia fina, que compreende todas as tarefas motoras finas, onde associa a função de coordenação dos movimentos dos olhos durante a fixação da atenção, e durante a fixação da atenção e manipulação de objetos que exigem controle visual, além de abranger as funções de programação, regulação e verificação das atividades preensivas e manipulativas mais finas e complexas. O motorgrosso, por sua vez, avalia fundamentalmente as condutas motoras intrinsecamente vinculadas à praxia global, que está relacionada com a realização e a automação dos movimentos globais complexos, que se desenrolam num determinado tempo e exigem a atividade conjunta de vários grupos musculares. Tanto os itens motor-fino adaptativo quanto motorgrosso avaliam aspectos referentes à tonicidade, que tem um papel fundamental no desenvolvimento motor. É ela que garante as atitudes, a postura, as mímicas, as emoções, de onde emergem todas as atividades motoras humanas. Por último, temos a linguagem que, por sua vez, refere-se ao processo de comunicação com o mundo, que inclui, além da fala, desde a percepção de sons à de imagens e expressões gestuais.

No entanto, alguns aspectos precisam ser mencionados ao caracterizarmos o teste Denver II. O primeiro deles refere-se ao fato de que o Denver II não é um teste de avaliação. O que ele faz é traçar observações a respeito de um momento do desenvolvimento em que se encontra a criança. Ele não deve ser comparado a um teste de QI, por exemplo. Por outro lado, é possível concluirmos que o teste Denver II se caracteriza por ser um teste flexível, o que possibilita que cada profissional faça a leitura dos dados de acordo com sua especificidade, de acordo com sua formação. Segundo Brêtas et al. (1995):

O TTDD II, devido a sua praticidade na aplicação, pode ser utilizado nos mais variados tipos de serviço de atendimento à criança, como: unidades básicas 
de saúde, ambulatórios, consultórios, clínicas, unidades pediátricas em hospitais, creches, préescolas, e serviços especializados em distúrbios do desenvolvimento infantil, permitindo a cada profissional uma leitura dos dados obtidos, de acordo com sua formação específica. (Brêtas et al., 1995).

Nesse sentido, o Teste Denver II encontra-se em consonância com os objetivos propostos pela pesquisa, já que os resultados obtidos a partir de sua aplicação possibilitam reflexões subsidiadas pelo saber psicológico. Encontramos ainda no Denver II um válido instrumento que nos auxilia na elaboração de intervenções precoces que potencializem o desenvolvimento infantil.

Conforme pudemos observar, o Denver II avalia quatro itens: as capacidades pessoais sociais; o desempenho motor fino adaptativo; o desempenho motor grosso; e a linguagem. Os itens que abordam a capacidade pessoal são avaliados a partir de tarefas como "alimentar boneca", em que a criança deve alimentar uma boneca com uma mamadeira de brinquedo; "remover e colocar roupas", relacionado a capacidade da criança em colocar e/ou remover peças de roupas como calças, meias, sapatos e jaquetas; "escovar os dentes com supervisão", em que os pais devem demonstrar como a criança escova os dentes e que tipo de ajuda recebe; e "lavar e secar as mãos", o que exclui a necessidade de a criança abrir torneiras.

Já o desempenho motor fino adaptativo relacionase à capacidade da criança de "empilhar uma torre de 6 cubos". O item motor grosso é avaliado por tarefas como "pular", "joga a bola de cima para baixo" e "chuta a bola para frente". No que se refere à linguagem, as capacidades averiguadas são: "nomear uma e quatro figuras", sendo que tais figuras são de animais cotidianos, como cachorro e gato; "apontar figuras", em que a criança deve discriminar uma figura em relação a outras; "partes do corpo", que se refere à capacidade da criança em reconhecer as partes do corpo humano; "fala - metade compreensível", que observa a clareza da fala da criança; "combina palavras", que diz da capacidade da criança de combinar pelo menos duas palavras que indiquem uma ação; e "conhece duas ações", sendo que essas ações são avaliadas com o auxílio de figuras e de perguntas como: "qual desses animais voa?", "qual deles late?".

O trabalho de campo buscava o levantamento de dados por meio da aplicação do teste Denver II em crianças dos dois grupos - pré-termo e a termo - e de um roteiro de anamnese em suas mães. Essas crianças eram provenientes da Maternidade Pública de Betim, em Minas Gerais, Brasil. Nossa amostra foi composta conforme caracterização de Laville \& Dionne (1999), isto é, uma amostra típica da população-alvo, explicitada a partir das necessidades do pesquisador.

As famílias que formavam a amostra se caracterizavam por: possuir estabilidade conjugal; buscar a assistência de saúde pública; ter crianças que nasceram com 30 a 34 semanas de idade gestacional, sem complicações clínicas, com peso médio de um quilo a dois quilos e que não apresentassem sequelas graves. Devido às dificuldades de contato com as famílias, a amostra de nossa pesquisa foi de quatro crianças: duas crianças pré-termo de 24 meses e suas mães e duas crianças a termo de 24 meses e suas mães. Optamos por realizar as entrevistas e a aplicação do Denver II nas casas das crianças, pois uma família solicitou que a avaliação fosse realizada na Universidade e o resultado do Denver II desta criança apresentou duas cautelas e duas falhas. Como se tratava de uma criança a termo, pensamos que o ambiente poderia ter influenciado no desempenho.

Assim, decidimos realizar a coleta em ambiente familiar, e não usar os resultados desta criança. Ao mesmo tempo em que a mãe respondia à anamnese, a criança era submetida ao teste Denver II. Foi possível observar em lócus uma amostra da relação existente entre mãe e criança. Antes do início do trabalho, conseguíamos um consentimento livre e esclarecido por parte das mães, para que assim o trabalho tivesse prosseguimento conforme exigência do Comitê de Ética. Para que a aplicação do teste não se tornasse fonte de preocupação por parte das mães, conversávamos um pouco com elas a respeito do resultado.

\section{Resultados}

No que compete às anamneses das crianças a termo, não se vê alterações significativas, pelo menos na fala das mães, nos aspectos motores e no aspecto de autonomia. $\mathrm{Na}$ verdade, percebe-se um esforço grande das mães em deixar que os filhos pratiquem as atividades sozinhos. Mas, por certo, ainda não desvincularam totalmente das crianças, o que nem é mesmo esperado, já que estas têm somente dois anos de idade.

Já a respeito das crianças pré-termo, foi relatada uma série de empecilhos e/ou uma sucessão de eventos que lembrava uma cadeia trágica em estilo grego, com muita dramaticidade. A impressão que transparece é a de que as crianças sobreviveram graças a numerosos milagres.

Um exemplo disso encontra-se na fala da mãe da criança 2:

Ela (a criança) saiu na sexta e levamos no domingo pra fazer exames. Ela fez muitos exames depois de nascer. Os médicos disseram que ela devia ter nascido cega e surda. No domingo, eu subi as escadas e meu marido me esperou pra depois subir com a nenê. Tava chuviscando e eu tomei aquela chuva. Comecei a suar frio e estava passando muito mal. Senti dores e quando vi a cesárea abriu e saiu um sangue preto. Queriam me internar porque eu sentia muita dor. A anestesia não pegava na pele e então costuraram.

Tive medo que não voltasse ao normal, tava preta. 
Quadro 1

Resultados do DENVER II segundo a relação de atividades propostas em ambos os grupos de estudo (crianças pré-termo e crianças a termo)

\begin{tabular}{|c|c|c|c|c|c|}
\hline SUBÁREAS & $\begin{array}{l}\text { ATIVIDADES } \\
\text { PROPOSTAS } \\
\end{array}$ & $\begin{array}{l}\text { Criança } 1 \\
\text { Prematura } \\
\end{array}$ & $\begin{array}{l}\text { Criança } 2 \\
\text { Prematura } \\
\end{array}$ & Criança 3 & Criança 4 \\
\hline \multirow{5}{*}{ PESSOAL-SOCIAL } & Lava e seca as mãos & $\mathrm{P}$ & $\mathrm{P}$ & $\mathrm{P}$ & $\mathrm{P}$ \\
\hline & $\begin{array}{l}\text { Escova os dentes com } \\
\text { supervisão }\end{array}$ & $\mathrm{P}$ & $\mathrm{P}$ & $\mathrm{P}$ & $\mathrm{P}$ \\
\hline & Põe roupas & $\mathrm{P}$ & $\mathrm{P}$ & $\mathrm{C}$ & $\mathrm{P}$ \\
\hline & Alimenta bonecas & $\mathrm{P}$ & $\mathrm{P}$ & $\mathrm{P}$ & $\mathrm{P}$ \\
\hline & Remove roupas & $\mathrm{P}$ & $\mathrm{P}$ & $\mathrm{P}$ & $\mathrm{P}$ \\
\hline \multirow{2}{*}{$\begin{array}{l}\text { MOTOR-FINO } \\
\text { ADAPTATIVO }\end{array}$} & Torre de 4 cubos & $\mathrm{P}$ & $\mathrm{P}$ & $\mathrm{P}$ & $\mathrm{P}$ \\
\hline & Torre de 6 cubos & $\mathrm{F}$ & $\mathrm{P}$ & $\mathrm{P}$ & $\mathrm{P}$ \\
\hline \multirow{8}{*}{ LINGUAGEM } & Combina palavras & $\mathrm{P}$ & $\mathrm{P}$ & $\mathrm{P}$ & $\mathrm{P}$ \\
\hline & $\begin{array}{l}\text { Fala metade } \\
\text { compreensível }\end{array}$ & $\mathrm{P}$ & $\mathrm{P}$ & $\mathrm{P}$ & $\mathrm{P}$ \\
\hline & Aponta duas figuras & $\mathrm{P}$ & $\mathrm{P}$ & $\mathrm{P}$ & $\mathrm{P}$ \\
\hline & Nomeia 1 figura & $\mathrm{P}$ & $\mathrm{P}$ & $\mathrm{P}$ & $\mathrm{P}$ \\
\hline & Partes do corpo & $\mathrm{P}$ & $\mathrm{P}$ & $\mathrm{P}$ & $\mathrm{R} / \mathrm{P}$ \\
\hline & Aponta quatro figuras & $\mathrm{F}$ & $\mathrm{F}$ & $\mathrm{P}$ & $\mathrm{P}$ \\
\hline & Conhece duas ações & $\mathrm{F}$ & $\mathrm{F}$ & $\mathrm{P}$ & $\mathrm{R} / \mathrm{P}$ \\
\hline & Nomeia quatro figuras & $\mathrm{F}$ & $\mathrm{F}$ & $\mathrm{P}$ & $\mathrm{P}$ \\
\hline \multirow{2}{*}{ MOTOR-GROSSO } & Pula & $\mathrm{F}$ & $\mathrm{P}$ & $\mathrm{P}$ & $\mathrm{P}$ \\
\hline & $\begin{array}{l}\text { Joga bola de cima para } \\
\text { baixo }\end{array}$ & $\mathrm{P}$ & $\mathrm{P}$ & $\mathrm{R} / \mathrm{P}$ & $\mathrm{P}$ \\
\hline
\end{tabular}

Legenda: P: passa, F: falha, R: recusa, C: cautela, NO: não foi possível testar

A injeção pra abrir [ter dilatação na hora do parto] fez eu sentir meu corpo pegando fogo. Na época eu estava com 18 anos. A médica disse pro meu marido que uma das duas iria morrer e era para ele escolher. $\mathrm{Na}$ hora que nasceu ela nem chorou, ela tava tão cansada de fazer força, porque há muito tempo que eu tava fazendo força, eu também nem tava aguentando mais. "Seu bebê nem está respirando", disse a médica, porque ela colocou um aparelho na minha barriga pra ver se o nenê estava respirando. Isso era 12:20 e 12:30 ela nasceu.

A vivência de ter um filho em um momento inesperado, já que comumente os bebês nascem com cerca de 38 semanas, marca profundamente as famílias, e principalmente as mães, que carregam em si mesmas uma culpa pelas intempéries quase que exclusiva. É possível observarmos, inclusive, que elas tentam compensar esse sentimento por outros meios, como o seio, por exemplo:

Ela vai até mim e pede pra mamar. Ela mama 10, 15 ou 5 minutos. "Toda vez pede o peito você dá?" Sim, responde ela. Às 19:00 vou à igreja ou fico assistindo Pica-Pau com ela até as 20:00, quando ela dorme (Mãe da Criança 2).

Para além dessa relação mediada pela culpa, ainda encontramos nas mães das crianças prematuras uma necessidade de ter o filho mais próximo, elemento que se torna visível na ação dessas mães de ainda amamentarem essas crianças, aprisionando as mesmas ao seu seio. 


\section{Discussão dos Resultados e Conclusão}

Seguindo as orientações do Manual do DENVER II (Frankenburg et al.,1990) para interpretação dos resultados, podemos concluir que existe uma diferença no desenvolvimento psicomotor de crianças prematuras em comparação com as crianças a termo. O manual revela que um resultado Normal refere-se a nenhuma falha e no máximo uma cautela, e o resultado Anormal apresenta duas ou mais falhas (Frankenburg et al.,1990).

As crianças prematuras apresentam um desenvolvimento anormal se comparadas à população em geral, pois faltaram em mais de duas tarefas. As duas crianças prematuras apresentaram três atrasos no campo da linguagem. No item "Apontar quatro figuras", dentro da população testada para a validação do teste, 50 a $75 \%$ das crianças conseguiram completar a tarefa (Frankenburg et al.,1990).. Nesse sentido, a falha das duas crianças prematuras tornase significativa. Nos itens "Conhecer duas ações" e "Nomear quatro figuras", $25 \%$ da amostra padrão realiza as atividades (Frankenburg et al.,1990); no entanto, as duas crianças a termo de nossa pesquisa conseguiram completar essas tarefas sem dificuldade.

Assim, podemos concluir que as crianças prematuras avaliadas na pesquisa apresentam um desenvolvimento psicomotor não adequado se comparadas com as crianças a termo. Associado a isso, é necessário observar que tanto aspectos cognitivos quanto psíquicos da criança podem vir a se tornar comprometidos, se retomarmos a ideia inicial de que o desenvolvimento humano se dá a partir de diversas interações entre os campos citados. Um exemplo disso refere-se aos atrasos na linguagem que encontramos em crianças prematuras: um atraso na linguagem pode também comprometer o desenvolvimento de habilidades sociais, relacionadas à forma como a criança interage com o outro, e até mesmo cognitivas, como o desenvolvimento do pensamento verbal, por exemplo. O que mais chama a atenção, no entanto, é o fato de uma área específica, a linguagem, ter sido prejudicada de maneira destoante, posto que ela se refere, em sua definição mais rudimentar, à capacidade de interação e de relacionamento com outros semelhantes. Podemos pensar que algo acontecia, algo que segurava essas crianças e não permitia o encontro delas com o mundo externo. $\mathrm{O}$ que seria?

As anamneses realizadas com as mães, dessa maneira, tornaram-se fundamentais para nos auxiliar em nosso processo investigativo. Percebemos por essas anamneses que as mães das crianças prematuras introduzem um elemento a mais na dinâmica, a saber: o aprisionamento/liberação dos filhos: as duas mães entrevistadas ainda amamentam suas crianças, o que ocorreu, inclusive, durante a aplicação da pesquisa de campo. Associado a isso, é importante mencionar que a busca pelo seio remete a uma busca pelo aconchego materno, ou por ambiente seguro, de confiança. É interessante pensar que a busca pelo seio aconteceu no momento da aplicação do DENVER II, momento em que as crianças se encontram com pessoas desconhecidas refugiando-se, portanto, no colo de suas mães. Recorrendo à ajuda da teoria de Erikson (1998), pudemos observar que o contraponto à esperança (qualidade do ego que surge a partir do conflito "confiança versus desconfiança") é o retraimento. Talvez a busca pelo seio seja um tratamento para uma situação em que esse retraimento se manifestou. Consequentemente, o desenvolvimento da autonomia, que é o que está em jogo na próxima etapa do Ciclo da Vida, parece-nos comprometido. As aplicações do teste e da anamnese, portanto, revelamnos que podem existir elementos a ser considerados por trás da aparente desenvoltura que apresentavam as crianças prematuras.

Todas as mães entrevistadas apresentam algum tipo de dificuldade na sua relação com o filho. A mãe da "criança 3" dorme com o filho, criando uma situação de dependência que, inclusive, aparece na dificuldade da criança em se vestir sozinha; a mãe da "criança 4" cria a ilusão de que sua filha tem um desenvolvimento acima da média. Contudo, o elemento amamentação, que só aparece nos casos das mães das crianças prematuras, parece-nos decisivo. A amamentação cria uma dependência concreta, confirmando a conclusão da pesquisa de Carvalho et al. (2001), que revela um agarramento da criança prematura com sua mãe.

Buscando ainda outras inter-relações em Erikson (1998), percebe-se que o aspecto de autonomia, nos pré-termos, pode, em certo nível, ser considerado um tanto refreado por cuidados extremados das mães na tentativa de compensar os eventos adversos, e negativos em sua maior parte, em toda a trajetória da criança. Além disso, a própria criança, ao mostrarse retraída, pode manifestar uma grande dificuldade em se lançar no mundo, em se afastar da proteção materna. Dificuldades surgem de ambos os lados, o que pode ser visto desse extremo como um indicador de um provável desencadeador de um adulto sem um vínculo geracional esperado e maduro, sem uma preparação para o "cuidar de si mesmo" (Erikson, 1998), preparação essa que consideramos, socialmente, ser a tarefa principal que adultos devem passar a seus filhos, esperada como fundamental e útil, constituída passo a passo desde a infância.

A ideia de Erikson (1998) de correlacionar o conflito "autonomia versus vergonha e dúvida" com o estágio anal-uretral e, a partir daí, com os verbos agarrar e deixar ir parece-nos sugestiva para pensar o movimento das mães das crianças prematuras, pois a ação de amamentar simboliza um agarrar. Este agarrar pode dificultar a comunicação dessas crianças com o mundo, elemento apresentado na interpretação 
dos resultados do DENVER II. Pois, o campo da linguagem avaliado através de "nomear uma e quatro figuras", "apontar figuras" e "conhece duas ações", como "qual destes animais late?" representou a falha das crianças prematuras. Acreditamos em um processo de codependência entre as mães e suas crianças prematuras. Se as mães puderem elaborar o trauma do nascimento prematuro, talvez possam liberar seus filhos para a autonomia.

Assim, o maior campo de intervenção junto ao tema da prematuridade parece-nos ser o campo das mães. Contudo, talvez seja necessário ficarmos atentos também as crianças, já que os resultados do primeiro conflito psicossocial são determinantes no desenvolvimento infantil, e talvez precisem ser trabalhados para que as crianças possam se relacionar com o mundo de uma maneira mais satisfatória. Cabe ao psicólogo usar de sua criatividade para intervir junto a elas.

\section{Referências Bibliográficas}

Brêtas J. R. S., Silva M. G. B., Silva C. V. A. (1995). Aplicação do Teste de Triagem do Desenvolvimento de Denver pelo Enfermeiro Pediatra: relato de caso. Acta Paulista de Enfermagem. 8: 9-16

Carvalho A. E. V., Linhares M. B. M., Martinez F. E. (2001). História de desenvolvimento e comportamento de crianças nascidas pré-termo e baixo peso $(<1.500 \mathrm{~g})$. Scielo - biblioteca eletrônica. Acessado de: //www.scielo.br/scielo.php?script=sci arttext\&pid=S0102-79722001000100002\& lng=pt\&nrm=iso. doi: 10.1590/S0102-79722001000100002

Chizzotti A. (1998). Pesquisa em ciências humanas e sociais (3 ed.). São Paulo: Editora Cortez.

Erikson E. H (1998). O ciclo de vida completo. Porto Alegre: Editora Artmed.

Fonseca V. (1995). Manual de observação psicomotora: significação_psiconeurológica dos fatores psicomotores. Porto Alegre: Editora Artes Médicas.

Frankenburg WK, Dodds J, Archer P, Bresnick B, Maschka
P, Edelman N, Shapiro H. (1990). Denver II Screening Manual. Denver, CO: Denver Developmental Materiais, Inc.

Guedes D. P., Guedes J. E. R. P. (1997). Crescimento, composição corporal e desempenho motor de crianças e adolescentes. São Paulo: Balieiro.

Isotani S. M. , Pedromônico M. R. M., Perissinoto J. , Kopelman B. I. (2002). O desenvolvimento de crianças nascidas pré-termo no terceiro ano de vida. A Folha Médica, 121: 85-92.

Laville C., Dionne J. (1999). A construção do saber. Porto Alegre: Editora Artes Médicas \& UFMG.

Le Boulch J. (1992). O desenvolvimento psicomotor: do nascimento aos 6 anos. (4 ed.) Porto Alegre: Editora Artmed.

Magalhães L. C., Barbosa V. M., Araújo A. R., Paixão M. L., Figueiredo E. M., Gontijo A. P. B (1999). Análise do desempenho de crianças pré-termo no teste de desenvolvimento de DENVER nas idades de 12,18 e 24 meses. Pediatria, 21, 330-339.

Martins H. H. T. S. (2004). Metodologia qualitativa de pesquisa. Educação e Pesquisa, 30: 289-300.

Méio M. D. B. B., Lopes C. S., Morsch D. S. (2003) . Fatores prognósticos para o desenvolvimento cognitivo de prematuros de muito baixo peso. Rev. Saúde Pública, 37:3p. Acessado em: $\quad$ www.scielo.br/scielo.php?script $=$ sci_arttext\&pid $=$ S003489102003000300008 \&lng=pt\&nrm=iso. doi: 10.1590/S003489102003000300008

Ministério da Saúde (2002). Manual do Método Mãe Canguru. Brasília: Ministério da Saúde.

Ministério da Saúde. Manual do Método Mãe canguru. Brasília: Ministério da Saúde, 2002.

Souza S. C., Leone C., Takano O. A., Moratelli H. B. (2008). Desenvolvimento de pré-escolares na educação infantil em Cuiabá, Mato Grosso, Brasil. Cad. Saúde Pública, 24. Acessado em: www.scielosp.org/scielo.php?script $=$ sci_arttext\&pid $=\mathrm{S} 0102$ 311X2008000800020\&lng=en\&nrm=iso. doi: 10.1590/S0102$311 \mathrm{X} 2008000800020$

\section{Sobre os autores}

Jacqueline de Oliveira Moreira - Doutora em Psicologia Clinica PUC-SP, Mestre em Filosofia - UFMG, Professora do Mestrado da PUC-MG, Psicóloga Clínica - Telefone: (31) 3223-3951 - Fax: (31) 3319-4568 E-mail: jackdrawin@yahoo.com.br

Diego Alonso Soares Dias - Graduando em Psicologia pela PUC-Minas/Betim - Endereço: Rua Pouso Alegre, 2442 - Santa Tereza. Belo Horizonte, MG. CEP: 31.010-514 - Telefone: (31) 3586-9865 E-mail: dasdias@gmail.com

Deusdenir de Souza Matis - Graduanda em Psicologia pela PUC-Minas/Betim - Endereço: Rua Esperança, 445 - Alvorada. Betim, MG. CEP 32.682-180 - Telefone: (31) 3591-5358

E-mail: deusdenir@yahoo.com.br

Maria Nazaré de Campos Silva - Graduanda em Psicologia pela PUC-Minas/Betim - Endereço: Cândido Cardoso de Miranda, 64, apto 201 - Jardim da Cidade. Betim, MG. CEP 32.652-030 - Telefone: (31) 87620078

E-mail: nazarefeliz1@yahoo.com.br 